\section{Cureus}

\title{
Developmental Venous Anomaly Associated with Hemi-Parkinson's Syndrome
}

\author{
Eric S. Nussbaum ${ }^{1}$, Archie Defillo ${ }^{2}$, Leslie Nussbaum $^{3}$ \\ 1. John Nasseff Neuroscience Institute, MN Neurovascular \& Skull Base Surgery, National Brain \\ Aneurysm Center at the John Nasseff Neuroscience Institute, MN Neurovascular \& Skull Base Surgery 2. \\ St. Joseph's Hospital, National Brain Aneurysm Center 3. National Brain Aneurysm Center, St. Paul, MN
}

$\square$ Corresponding author: Eric S. Nussbaum, lnussbaum@comcast.net

Disclosures can be found in Additional Information at the end of the article

\section{Abstract}

Objective and Importance: Developmental venous anomalies (DVAs) are common congenital anomalies of intracranial venous drainage. In general, it is felt that DVAs replace the normal venous drainage system and, unless associated with another lesion such as a cavernous malformation, should not produce symptoms. The present case raises important questions regarding the potential for DVAs to become symptomatic and the role of venous hypertension in this process.

Clinical Presentation: We present the case of a 23-year-old woman who presented with rapidly progressive hemi-parkinsonism consisting of unilateral tremor, micrographia, gait difficulty, and cogwheel rigidity. MRI demonstrated a large DVA draining the region of the contralateral basal ganglia with associated high signal intensity on T2-weighted MR imaging and gadolinium enhancement. Arteriography demonstrated only the DVA with the trunk of the angioma draining forward toward the inferior petrosal sinus instead of into the deep venous system. A focal stricture of the main venous trunk was noted. Retrograde venography confirmed a tight stricture at the entrance of the venous trunk into the cavernous sinus.

Conclusions: Although DVAs are generally considered benign variants of normal venous drainage, it is possible that in select cases, venous outflow restriction may result in symptomatic venous hypertension. This may be particularly problematic in the setting of a large DVA when multiple radicular veins drain into a single large venous channel.

Categories: Neurosurgery

Keywords: parkinson's disease, cerebral vascular malformation, developmental venous anomaly, venous angioma, venous hypertension

Received 12/24/2012 Review began 12/25/2012 Published 01/02/2013

\section{(C) Copyright 2013}

Nussbaum et al. This is an open access article distributed under the terms of the Creative Commons Attribution License CC-BY 3.0., which permits unrestricted use, distribution, and reproduction in any medium, provided the original author and source are credited.

\section{Introduction}

Developmental venous anomalies (DVAs) are congenital anomalies of intracranial venous drainage that replace the normal draining veins of the surrounding brain [1, 4]. They have been found in infants and children, and it has been postulated that they may result from intrauterine occlusion or maldevelopment of normal medullary veins [4]. We describe the case of a patient with a DVA that formed the venous drainage of the basal ganglia. The patient presented with progressive hemi-parkinsonism,possibly related to venous hypertension. To our knowledge, this is one of the first reports of such a sequence of events. This case suggests the potential importance of venous outflow restriction in the development of symptoms in a DVA. 


\section{Cureus}

\section{Case Presentation}

This 23-year-old right-handed woman presented with three month history of progressively worsening right-sided tremor, loss of right hand dexterity and walking difficulty. Neurological examination revealed the unilateral tremor, micrographia, cogwheel rigidity, and gait difficulty. Magnetic resonance imaging (MRI) scan demonstrated the large DVA with contrast enhancement and abnormal signal change within the associated basal ganglia (Figure 1). T2weighted imaging revealed signal change compatible with edema in the basal ganglia. Diffusion-weighted imaging showed no true ischemia but did reveal abnormal signal hyperintensity presumably related to the significant edema.

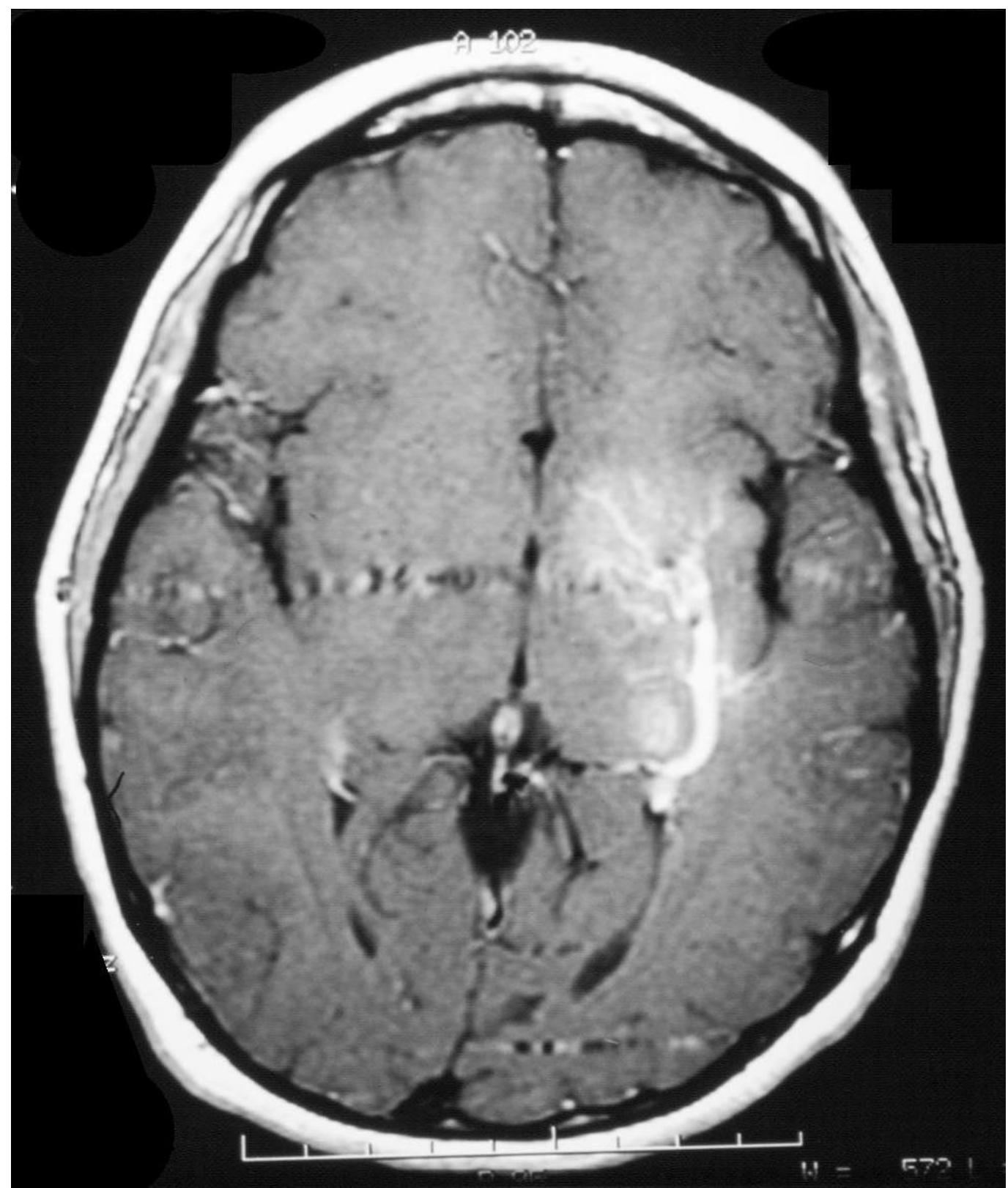

FIGURE 1: Axial, contrast-enhanced, T1-weighted MR image shows the large DVA with associated contrast enhancement and abnormal signal change within the surrounding parenchymal tissue. 


\section{Cureus}

Cerebral angiography confirmed the large DVA and also showed a stenosis involving the large venous trunk representing the primary outflow of the DVA (Figure 2).

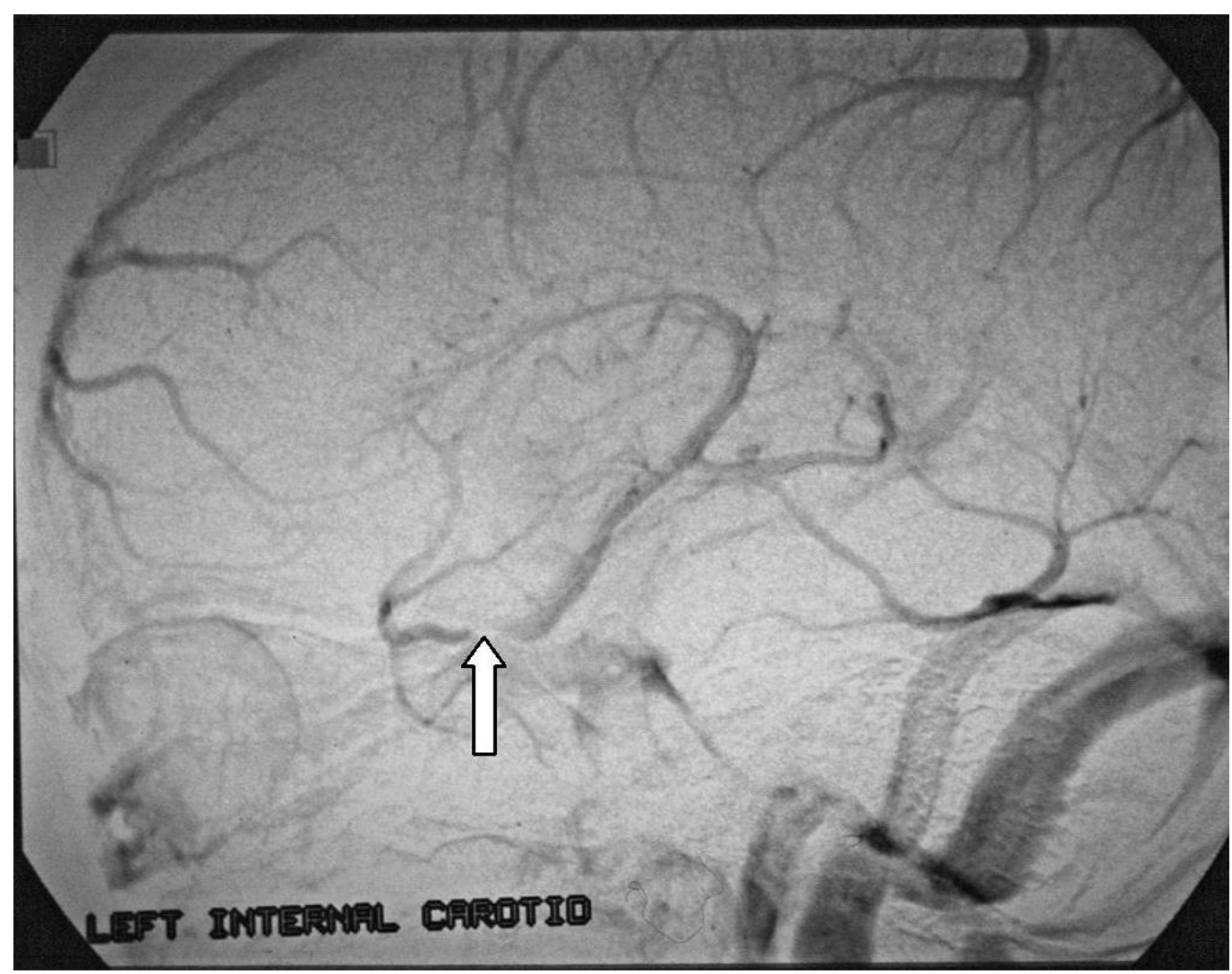

FIGURE 2: Lateral venous phase angiographic injection of the left internal carotid artery demonstrates the large caput type appearance of a DVA.

Lateral venous phase angiographic injection of the left internal carotid artery demonstrates the large caput type appearance of a DVA with stenosis (arrow) involving the primary venous outflow of the DVA

The possibility of balloon dilatation of the venous stricture was considered, but a catheter could not be advanced across the narrowing. The patient was managed with dopamine and responded well with a significant improvement in her symptoms. In addition, she was maintained on aspirin at $325 \mathrm{mg}$ per day. At two year follow-up, she remained stable neurologically and then relocated from the area when she was lost to follow-up.

\section{Discussion}

The DVA represents a congenital malformation composed entirely of veins with normal intervening neural parenchyma in which a network of small medullary veins converges into a large central venous channel that drains into the superficial or deep venous system [1, 4]. This configuration results in the classic "caput medusa" appearance on angiography. Prior to the development of high resolution MR imaging, it had been felt that DVA's could result in bleeding, and some surgeons aggressively removed DVA's in the setting of hemorrhage, particularly in the posterior fossa. Over time, it became clear that these DVA's were almost always associated with a cavernous malformation that represented the true source of bleeding 
in these cases [1]. In general, surgery is reserved for those cases in which an associated cavernous malformation can be identified as the source of bleeding. Because the DVA represents a normal and often critical venous drainage pathway for blood flow exiting the brain, direct surgical treatment aimed at excising or partially removing a DVA is contraindicated.

The notion that a DVA can produce symptoms by itself is controversial, but isolated reports have described either obstructive hydrocephalus, venous infarction, hemorrhage, or other symptoms arising from a DVA without another associated vascular abnormality [3, 5-15]. Based on our case and these other isolated reports, it would appear that stenosis or occlusion of one of the venous radicles or the main trunk of the lesion could result in venous hypertension or ischemia. In fact, the abnormal drainage pattern might predispose to such a situation if the main draining trunk were compromised given the potential lack of normal collateral venous drainage channels.

The documented venous outflow limitation associated with abnormal MR signal surrounding the DVA in our case further supports the likely relationship between the DVA and the development of basal ganglia symptoms in our patient. It is possible that over time, individuals with similar venous outflow limitation will develop new venous collateral pathways which could result in symptomatic improvement.

\section{Conclusions}

Although DVAs are traditionally felt to be benign entities, the clinical picture and imaging studies in this case suggest that DVAs may become symptomatic. We postulate an impaired venous outflow resulting in "venous ischemia" as the pathophysiology.

\section{Additional Information}

\section{Disclosures}

Human subjects: Consent was obtained by all participants in this study. Conflicts of interest: In compliance with the ICMJE uniform disclosure form, all authors declare the following:

Payment/services info: All authors have declared that no financial support was received from any organization for the submitted work. Financial relationships: All authors have declared that they have no financial relationships at present or within the previous three years with any organizations that might have an interest in the submitted work. Other relationships: All authors have declared that there are no other relationships or activities that could appear to have influenced the submitted work.

\section{References}

1. Abe, M., Asfora, W.T., DeSalles, A.A.F., Kjellberg, R.N: Cerebellar venous angioma associated with angiographically occult brain stem vascular malformation. Report of two cases. Surg Neurol . 1990, 33:400-403. http://dx.doi.org/10.1016/0090-3019(90)90152-F

2. Camacho DLA, Smith JK, Grimme JD, Keyserling HF, Castillo M: Atypical MR imaging perfusion in developmental venous anomalies. AJNR- AM J Neuroradiol. 2004, 25:1549-52.

3. Kumabe T, Kayama T, Sakurari Y, Ogasawara K, Niizuma H, Wada T, Namiki T: Encapsulated chronic intracerebral hematoma caused by venous angioma of the basal ganglia: a case report. No Shinkei Geka . 1990, 18:735-39.

4. Truwit CL: Venous angioma of the brain: history, significance, and imaging findings . AJR . 1992, 159:1299-1307.

5. Avman N, Dincer C: Venous malformation of the aqueduct of sylvius treated by interventriculostomy: 15 years follow-up. Acta Neurochirurgica. 1980, 32:219-24. http://dx.doi.org/10.1007/BF01402077

6. Krauss JK, Pohle T, Borremans JJ: Hemichorea and hemiballism associated with contralateral 
hemiparesis and ipsilateral basal ganglia lesions. Mov Disord . 1999, 14:497-501.

10.1002/1531-8257(199905)14:3<497::AID-MDS1019>3.0.CO;2-X

7. Kalia LV, Mozessohn L, Aviv RI, et al: Hemichorea-hemiballism associated with hyperglycemia and a developmental venous anomaly. Neurology. 2012, 78:838.

http://dx.doi.org/10.1212/WNL.0b013e318249f733

8. Guhl S, Kirsch M, Lauffer H, Fritsch M, Schroeder HW: Unusual mesencephalic developmental venous anomaly causing obstructive hydrocephalus due to aqueduct stenosis. J Neurosurg Pediatr . 2011, 8:407-10. http://dx.doi.org/10.3171/2011.7.PEDS114

9. Sepelyak K, Gailloud P, Jordan LC: Thrombosis of a developmental venous anomaly with hemorrhagic venous infarction. Arch Neurol. 2010, 67:1028.

http://dx.doi.org/10.1001/archneurol.2010.176

10. Dehkharghani S, Dillon WP, Bryant SO, Fischbein NJ: Unilateral calcification of the caudate and putamen: association with underlying developmental venous anomaly. Am J Neuroradiol. 2010, 31:1848-52. http://dx.doi.org/10.3174/ajnr.A2199

11. Fenzi F, Rizzuto N: Ataxia and migraine-like headache in a girl with cerebellar developmental venous anomaly. J Neurol Sci. 2008, 273:127-29. http://dx.doi.org/10.1016/j.jns.2008.06.004

12. Giannetti AV, Rodrigues RB, Trivelato FP: Venous lesion as a cause of sylvian aqueductal obstruction; case report. Neurosurgery. 2008, 62:E1167-68. http://dx.doi.org/10.1227/01.neu.0000325882.21118.7d

13. Brasse G, Stammel O, Siemens P, Topper R.: Thrombosis of developmental venous anomaly and consecutive venous infarction. Nervenarzt. 2008, 79:703-5. 10.1007/s00115-008-2457-7

14. Hammoud D, Beauchamp N, Wityk R, Yousem D: Ischemic complication of a cerebral developmental venous anomaly: case report and review of the literature. J Comput Assist Tomogr. 2002, 26:633-36. http://dx.doi.org/10.1097/00004728-200207000-00028

15. Konan AV, Raymond J, Bourgouin P, Lesage J, Millot G, Roy D: Cerebellar infarct caused by spontaneous thrombosis of a developmental venous anomaly of the posterior fossa. Am J Neuororadiol. 1999, 20:256-58. 